\title{
A composite score combining procalcitonin, C-reactive protein and temperature has a high positive predictive value for the diagnosis of intensive care-acquired infections
}

\author{
Laurent Robriquet ${ }^{1,4^{*}}$, Caroline Séjourné ${ }^{\prime}$ Eric Kipnis², Michele D'herbomez ${ }^{3}$ and François Fourrier ${ }^{1}$
}

\begin{abstract}
Background: Nosocomial infection diagnosis in the intensive care unit (ICU) remains a challenge. We compared routine measurements of procalcitonin (PCT), C-reactive protein (CRP), white blood cell count (WBC) and temperature in the detection of ICU-acquired infections.

Method: Prospective observational cohort study in a University hospital Medicosurgical ICU. All patients admitted to the ICU $\geq 5$ days ( $n=141$ ) were included into two groups, either infected (documented infection, $n=25$ ) or non-infected (discharged from the ICU without diagnosis of infection, $\mathrm{n}=88$ ).

Results: PCT, CRP, WBC and temperature progression from day -4 (D-4) to day 0 (D0) (day of infection diagnosis or ICU discharge) was analysed. Differences $(\Delta)$ were calculated as D0 levels minus the lowest preceding value. DO PCT and CRP were significantly increased in infected compared to non-infected patients (median, $1^{\text {st }}$ and $3^{\text {rd }}$ quartiles): $3.6 \mathrm{ng} / \mathrm{mL}(0.92-25)$ for PCT, $173 \mathrm{mg} / \mathrm{L}$ (126-188) for CRP versus $0.02 \mathrm{ng} / \mathrm{mL}(0.1-0.9)$ and $57 \mathrm{mg} / \mathrm{mL}(31-105)$ respectively $(p<0.0001)$. In multivariate analysis, $D 0$ temperature $>38.6^{\circ} \mathrm{C}, P C T>1.86 \mathrm{ng} / \mathrm{mL}$, and $C R P>88 \mathrm{mg} / \mathrm{L}$, performed well (AUCs of $0.88,0.84$, and 0.88 respectively). The sensitivity/specificity profiles of each marker (76\%/94\% for temperature, $68 \% / 91 \%$ for PCT, and $92 \% / 70 \%$ for CRP) led to a composite score $(0.068 \times$ D0 PCT + $0.005 \times \mathrm{D} 0 \mathrm{CRP}+0.7 \times$ temperature) more highly specific than each component (AUC of 0.90 and sensitivity/ specificity of $80 \% / 97 \%)$.
\end{abstract}

Conclusion: Combining CRP, PCT and temperature is an approach which may increase of nosocomial infection detection in the ICU.

Keywords: Nosocomial infection, Procalcitonin, C-reactive protein, Intensive care unit

\section{Background}

Early identification of nosocomial infections is crucial to therapeutic decision-making, allowing both early antimicrobial therapy and source eradication which determine outcome [1]. However, early discrimination between sepsis due to nosocomial infection (NI) and systemic inflammatory response syndrome (SIRS) is challenging in clinical practice. Indeed, in early sepsis, clinical signs

\footnotetext{
*Correspondence: laurent.robriquet@chru-ille.fr

'Service de Réanimation Polyvalente, Centre Hospitalier Universitaire de Lille, 59000 Lille, France

${ }^{4}$ Service de Réanimation Polyvalente, Hôpital Roger Salengro - Centre Hospitalier Universitaire de Lille, Rue Emile Laine, 59037 Lille, Cedex France Full list of author information is available at the end of the article
}

related to the focus of infection may be minimal or obscured by non-specific symptoms of SIRS common to various non-infectious inflammatory conditions. Definitive diagnosis of infection is defined as the identification of pathogens in a biological sample from a normally sterile tissue or fluid [2]. However, this definition still relies on clinical suspicion of infection since colonizing pathogens may be present without leading to the pathogen-related damage which defines infection [2]. The reliance of diagnosis on clinical suspicion rather than identification of pathogens is particularly true for nosocomial infection which occurs in hospitalized patients, increasingly colonized by various pathogens over 
time. This absence of any "gold-standard" of infection (with some exceptions such as bacterial meningitis, fungemia etc....) has resulted in a decades-long quest for biomarkers of infection capable of assisting or even redefining the diagnosis of infection.

In the ICU, early, sensitive, and specific laboratory tests would be crucial to guide clinicians in identifying infected patients who could benefit from prompt empirical antibiotic therapy and to avoid unnecessary antibiotic treatments.

The aim of our prospective cohort study was to test the hypothesis that inflammatory biomarkers procalcitonine (PCT) and C-reactive protein (CRP), in addition to routine biomarkers such as white blood-cell count (WBC) and clinical markers such as fever, could assist in the early identification of patients with ICU-acquired nosocomial infection.

\section{Methods}

\section{Study design and inclusion criteria}

This prospective observational study was conducted in a 16-bed medico-surgical university ICU from July 2007 to March 2008. Ethics committee approval was obtained from the French Society of Intensive Care Medicine (SRLF-CE-157) for our trial and written informed consent was obtained from each patient or designated surrogate. All patients who were aged $>18$ years admitted the ICU for more than 4 days were eligible. Only the first admission to the ICU was recorded. Patients were excluded if they were pregnant, already included in another trial, or undergoing care limitation or withdrawal.

\section{Definitions}

Clinically suspected VAP was defined as a new or persistent pulmonary infiltrate on the chest radiograph, with at least two of the following criteria: (i) temperature $>38^{\circ} \mathrm{C}$ or $<36^{\circ} \mathrm{C}$; (ii) $\mathrm{WBC}>10$ or $<4 \times 10^{3} / \mathrm{mm}^{3}$; (iii) purulent tracheal aspirate $[3,4]$. Microbiological confirmation was defined by the presence of at least one potentially pathogenic microorganism in respiratory samples according to predefined thresholds (bronchoalveolar lavage fluid samples yielding $10^{4} \mathrm{CFU} / \mathrm{mL}$ or tracheal aspirates yielding $10^{6} \mathrm{CFU} / \mathrm{mL}$ ).

Bloodstream infection (BSI) was defined as the occurrence of infection associated with one or more positive blood culture results unrelated to an infection incubating at ICU admission. In case of coagulase-negative Staphylococci, two positive blood cultures on separate occasions within a 48-hrs period, and confirmation of clinical significance by the attending intensivist were required for diagnosis of bacteremia [5]. All Other ICUacquired infections were defined according to the modified Centre for Disease Control and Prevention criteria [6]. Blood cultures were routinely performed when the patients' temperature was $\geq 38.5^{\circ} \mathrm{C}$ or $<36^{\circ} \mathrm{C}$ or when infection was suspected on clinical grounds.

SIRS was diagnosed in the presence of more than one of the following clinical findings: (i) body temperature higher than $38^{\circ} \mathrm{C}$ or lower than $36^{\circ} \mathrm{C}$, (ii) heart rate higher than 90 beats per min, (iii) hyperventilation evidenced by respiratory rate higher than $20 /$ min or arterial partial pressure of carbon dioxide $\left(\mathrm{PaCO}_{2}\right)$ lower than $32 \mathrm{mmHg}$, (iv) $\mathrm{WBC}$ higher than 12000 cells $/ \mu \mathrm{L}$ or lower than 4000 cells $/ \mu \mathrm{L}$.

\section{Study design and data collection}

We followed a previously described design and protocol for data collection [7]. Briefly, "non-infected" patients had no bacteriological or clinical signs of nosocomial infections and "infected" patients were those with ICUacquired, therefore nosocomial, infection. For analysis, only the first episode of nosocomial infection was considered. Day 0 (D0) was defined as the day of nosocomial infection diagnosis for infected patients or the day of ICU discharge for non-infected patients. Daily values of PCT, CRP, temperature, WBC and SOFA score from four days prior to day 0 (D-4) up to day 0 (D0) ware collected and analysed comparing infected and noninfected patients. For comparisons, daily values on D0 and D-4 were considered as well as biomarker variations over time $(\triangle \mathrm{PCT}$ and $\triangle \mathrm{CRP})$ calculated as the difference between D0 value minus the lowest PCT and CRP value over the previous 4 days.

Collected data included age, gender, admission diagnosis, systemic inflammatory response syndrome (SIRS), Simplified Acute Physiology Score II (SAPS II), Sequential Organ Failure Assessment (SOFA) score, central vein catheterization and dwell time, mechanical ventilation and duration, anti-infectious treatment, ICU length of stay and patient outcome [8]. PCT, CRP and WBC were measured at admission and daily until ICU discharge or death in all patients. Body temperature was measured every three hours and daily lowest and highest values were recorded. Patients were assessed daily for clinical evidence of infection, and appropriate samples for bacteriological cultures were collected whenever infection was suspected.

\section{Biomarkers}

Blood samples were obtained from an arterial line upon admission and subsequently daily at 07:00. PCT was measured by time-Resolved Amplified Cryptase Emission technology in a Kryptor ${ }^{\circledR}$ analyser (Brahms Diagnostica, Berlin, Germany). The sensitivity of the assay was $0.05 \mathrm{ng} / \mathrm{mL}$. CRP was measured by an immunoturbidimetric assay (Advia 2400, Bayer Diagnostics, Tarrytown, NY). WBC was quantified by the hospital 
hematology laboratory using an automated cell analyser (XE 20100, Sysmex, Japan).

\section{Statistical analysis}

All results are presented as number (percentage) for categorical variables and median and $25^{\text {th }} / 75^{\text {th }}$ percentiles for quantitative variables (data non-normally distributed). The Kolmogorov-Smirnov test was used to assess sample distributions. Continuous variables were compared using the Mann-Whitney (2-group comparison) or Kruskall Wallis (multiple-group comparison) nonparametric tests. Categorical variables were compared with the $\chi^{2}$ or the Fisher's exact test, as appropriate. All $\mathrm{p}$ values were two-tailed. Statistical significance was defined as $\mathrm{p}<0.05$. Time-dependent analysis of different variables was performed with a general linear model, univariate repeated-measures analysis using a split-plot design approach. We studied PCT, CRP, temperature, $\mathrm{WBC}$ at $\mathrm{D} 0$ and $\mathrm{D}-4$, the $\triangle \mathrm{PCT}$ and $\triangle \mathrm{CRP}$ in a univariate analysis. Multivariate regression logistic analysis was used to determine values independently associated with ICU-acquired infection and Odds ratio (OR) with 95\% confidence interval (CI) were calculated. Receiver-operating characteristic (ROC) curves and the areas under the curve (AUC) were determined for PCT, CRP, temperature, $\mathrm{WBC}$ at $\mathrm{D} 0$ and for the $\triangle \mathrm{PCT}$ and $\triangle \mathrm{CRP}$. The AUC values are reported with the $95 \%$ confidence interval. In medical practice, a diagnostic test with an AUC $<0.75$ would be regarded as non contributive. Sensitivities, specificities, positive predictive values and negative predictive values were calculated from crosstabulations. A composite score was determined using the best values predicting nosocomial infection. Statistical analyses were performed using the SAS software version 8.2 (SAS Institute Inc., Cary, NC, USA).

\section{Results}

During the study period, 267 patients were admitted to our ICU. One hundred and twenty-six patients were excluded ( 24 obstetrical patients, 8 patients under 18 years of age, 81 patients who stayed less than 4 days, and 4 patients who had treatment limited or withdrawn). One hundred and forty-one patients were included in the study, 116 non-infected among which 88 were non-infected and discharged alive from the ICU. Twenty-five patients were diagnosed with infections acquired in the ICU.

Age, sex distribution and severity of illness upon ICU admission were not statistically different between patients with ICU-acquired infection $(\mathrm{n}=25)$ and noninfected $(\mathrm{n}=88)$ (Table 1). Concerning ICU-acquired infections, 11 BSI, 9 VAP, 2 catheter-related infections and 3 fungemia were recorded. Nosocomial infection occurred 11 days (8-14) after ICU admission. The median number of days without antibiotics before nosocomial
Table 1 Characteristics of the 113 studied patients during ICU stay

\begin{tabular}{|c|c|c|c|}
\hline $\begin{array}{l}\text { Characteristics of } \\
\text { patient population }\end{array}$ & $\mathrm{NI}-(88)$ & $\mathrm{NI}+(25)$ & $p$ \\
\hline Age (years) & $55(45-65)$ & $55(47-59)$ & 0.34 \\
\hline Sex (male/female) & $48 / 40$ & $17 / 8$ & 0.38 \\
\hline SAPS $\|$ score at admission & $45(31-55)$ & $50(38-57)$ & 0.43 \\
\hline Admission diagnosis, n (\%) & & & 0.07 \\
\hline Acute respiratory failure & $26(30)$ & $5(20)$ & \\
\hline Neurologic failure & $22(25)$ & $5(20)$ & \\
\hline Cardiovascular failure & $16(18)$ & $3(12)$ & \\
\hline Polytrauma & $10(11)$ & $6(24)$ & \\
\hline Post operative & $3(3)$ & $5(20)$ & \\
\hline Miscellaneous & $11(13)$ & $1(4)$ & \\
\hline \multicolumn{4}{|l|}{ Site of infection, n (\%) } \\
\hline Bacteremia & & $11(44)$ & \\
\hline Pneumonia & & $9(36)$ & \\
\hline Catheter related infection & & $2(8)$ & \\
\hline Candidemia & & $3(12)$ & \\
\hline Delay of $\mathrm{NI}$, days & & $11(8-14)$ & \\
\hline $\begin{array}{l}\text { Number of days without } \\
\text { antibiotics before NI }\end{array}$ & & $5(3.5-5.5)$ & \\
\hline Central venous catheter, n (\%) & $60(68)$ & $25(100)$ & 0.005 \\
\hline $\begin{array}{l}\text { Duration of central venous } \\
\text { catheter, days }\end{array}$ & $11(8-17)$ & $22(14-35)$ & 0.001 \\
\hline $\mathrm{MV}, \mathrm{n}(\%)$ & $58(66)$ & $24(96)$ & 0.02 \\
\hline Duration of MV, days & $10(5-14)$ & $25(15-33)$ & 0.0007 \\
\hline Length of ICU stay, days & $12(7-18)$ & $29(22-39)$ & $<0.0001$ \\
\hline
\end{tabular}

infection diagnosis was 5 days (3.5-5.5) and the median of duration of mechanical ventilation and length of ICU stay were significantly higher in patients with ICUacquired infection compared to non-infected patients: 25 days (15-33) vs. 10 days $(5-14), \mathrm{p}<0.001$; and 29 days (22-39) vs. 12 days $(7-18), \mathrm{p}<0.0001$. SIRS criteria were present at D0 in $100 \%$ of infected patients vs. $74 \%$ of non-infected patients $(\mathrm{p}=0.01)$. The median of SOFA score was significantly higher in infected compared to non-infected patients: $8(6-12)$ vs. $1(0-3.5)$ at D0 and 7 (5-9) vs. $3(2-6)$ at $\mathrm{D}-4, \mathrm{p}<0.001$. Time-dependent analysis of both PCT and CRP during the 4 days prior to diagnosis of nosocomial infection showed a significant increase in infected patients whereas PCT and CRP levels decreased over the time in the non-infected group (Figure 1). PCT and CRP D0 median concentrations were both significantly increased in the infected group compared non-infected group, $3.6 \mathrm{ng} / \mathrm{mL}(0.92-25)$ vs. $0.2 \mathrm{ng} / \mathrm{mL}(0.1-0.9)$ and $173 \mathrm{mg} / \mathrm{L} \mathrm{(126-188)} \mathrm{vs.} 57 \mathrm{mg} / \mathrm{L}$ (31-101), p $<0.001$, respectively. A similar result was obtained for maximal daily temperature: the median value of 

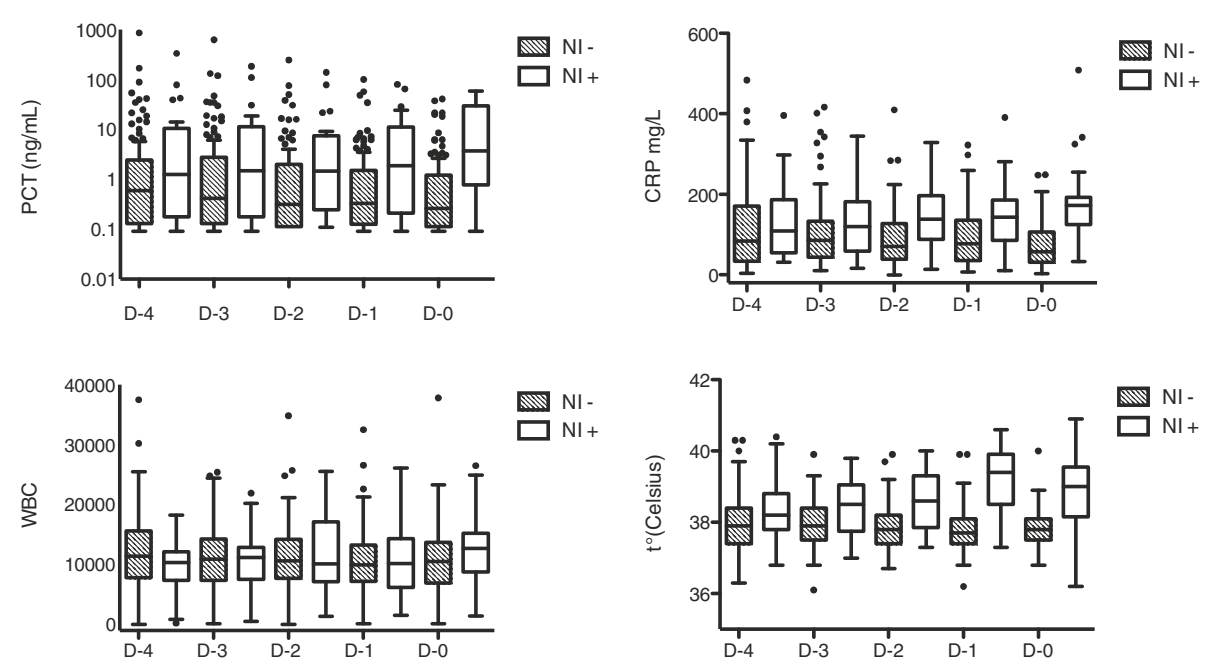

Figure 1 Dynamics of serum PCT and CRP concentrations, WBC and temperature in patients-acquired ICU infection and non-infected patients from D-4 to D0. Nl: nosocomial Infection. Data are presented as box plot. *: $p<0.05$.

maximal daily temperature at D0 was significantly increased in the infected group compared to the non-infected one: $39^{\circ} \mathrm{C}(38.2-39.5)$ versus $37.8^{\circ} \mathrm{C}(37.5-38.1), \mathrm{p}<0.001$. WBC values from D-4 to D0 were not significantly different between infected and non-infected patients. Dynamic data on PCT, CRP, WBC and temperature from D-4 to D0 are shown in Figure 1.

Variables included in the univariate logistic regression model for identification of patients with ICU-acquired infection were: PCT, CRP, WBC, and maximal daily temperature at both D-4 and D0, $\triangle \mathrm{PCT}$ and $\triangle \mathrm{CRP}$. Results are shown in Table 2 . No D-4 parameters were significantly different between infected and non-infected patients and were not studied further. All D0 parameters, except D0 WBC, were significantly different between infected and non-infected patients and D0 WBC was included in subsequent analyses for comparison. Analysis of the time course, as expressed by $\triangle \mathrm{PCT}$ and $\triangle \mathrm{CRP}$ levels, showed that the median $\triangle \mathrm{PCT}$ in patients with ICU-acquired infection was $1.6 \mathrm{ng} / \mathrm{mL}(0.06-7.01)$ vs. $0(0-0)$ in non-infected patients $(\mathrm{p}<0.0001)$ and $\triangle \mathrm{CRP}$ was $75 \mathrm{mg} / \mathrm{L}(37-130)$ vs $0.5 \mathrm{mg} / \mathrm{L}(0-21), \mathrm{p}<0.0001$. Stepwise logistic regression independently identified three factors in early identification of ICU-acquired infections: PCT level at D0 (OR: 1.09; 95\% CI: 1.03-1.16), maximal daily temperature at D0 (OR: 3.07 ; 95\% CI: 1.53-6.14) and $\triangle$ CRP (OR: 1.02; 95\% CI: 1-1.03) (Table 3). Although $\triangle \mathrm{PCT}$ was not significant in multivariate analysis, we included it in subsequent analyses for comparison.

ROC curves were plotted to compare the detection of nosocomial infection by PCT, CRP, WBC, and temperature at D0. The AUC of D0 WBC was poor of only 0.62. However the AUC for D0 temperature was 0.88 and temperature at $\mathrm{D} 0>38.6^{\circ} \mathrm{C}$ resulted in a sensitivity/ specificity of $76 \% / 94 \%$. AUCs for PCT and CRP D0 were 0.84 and 0.88 respectively, and were not significantly different $(\mathrm{p}=0.67)$ indicating that the tests globally performed similarly in discriminating nosocomial infection.

\section{Table 2 Results of univariate analysis}

\begin{tabular}{|c|c|c|c|}
\hline & $\mathrm{NI}-(\mathbf{8 8})$ & $\mathrm{NI}+(25)$ & $p$ \\
\hline PCT D-4 (ng/mL) & $0.44(0.12-1.82)$ & $1.25(0.18-9.2)$ & 0.18 \\
\hline PCT D0 (ng/mL) & $0.2(0.1-0.9)$ & $3.6(0.92-25)$ & $<0.0001$ \\
\hline CRP D-4 (mg/L) & $84(34-164)$ & 109 (59-179) & 0.18 \\
\hline CRP DO (mg/L) & $57(31-105)$ & $173(126-188)$ & $<0.0001$ \\
\hline WBC D-4 (cells/mm $\left./ \mathrm{m}^{3}\right)$ & $11430(7900-15600)$ & $10320(7445-11955)$ & 0.28 \\
\hline WBC D0 (cells/mm³) & $10540(7115-13512)$ & $12680(8800-13500)$ & 0.08 \\
\hline Temperature $\mathrm{D}-4\left({ }^{\circ} \mathrm{C}\right)$ & $37.9(37.4-38.4)$ & $38.2(37.8-38.7)$ & 0.08 \\
\hline Temperature D0 $\left({ }^{\circ} \mathrm{C}\right)$ & $37.8(37.5-38.1)$ & $39(38.2-39.5)$ & $<0.0001$ \\
\hline$\Delta \mathrm{PCT}(\mathrm{ng} / \mathrm{mL})$ & $0(0-0)$ & $1.6(0,06-7.01)$ & $<0.0001$ \\
\hline$\Delta \mathrm{CRP}(\mathrm{mg} / \mathrm{L})$ & $0.5(0-21)$ & $75(37-130)$ & $<0.0001$ \\
\hline
\end{tabular}


Table 3 Results of multivariable logistic regression model

\begin{tabular}{lll}
\hline & Odds ratio & $\mathbf{9 5 \%}$ confidence interval \\
\hline PCT D0 $(\mathrm{ng} / \mathrm{mL})$ & 1.09 & $1.03-1.16$ \\
\hline Température D0 $\left({ }^{\circ} \mathrm{C}\right)$ & 3.07 & $1.53-6.14$ \\
\hline$\Delta C R P(\mathrm{mg} / \mathrm{L})$ & 1.02 & $1-1.03$ \\
\hline Variations per unit of measurement &
\end{tabular}

However, using the best cut-offs for PCT and CRP D0 values which were $1.86 \mathrm{ng} / \mathrm{mL}$ and $88 \mathrm{mg} / \mathrm{L}$ respectively, the resulting sensitivity/specificity were inverted: low specificity/high sensitivity of $68 \% / 91 \%$ for PCT and high sensitivity/low specificity of $92 \% / 70 \%$ for CRP. The best cut-off values and AUCs for all clinical and biological makers are shown in Table 4 and ROC curves are represented in Figure 2. The combination of the three markers with AUCs $>0,8$ over their respective optimal thresholds, D0 PCT $>1.86 \mathrm{ng} / \mathrm{mL}$, D0 CRP $>88 \mathrm{mg} / \mathrm{L}$ and D0 temperature $>38^{\circ} \mathrm{C}$, was present in $56 \%$ of infected patients compared to $1 \%$ of non-infected patients. A composite marker was therefore constructed, combining PCT, CRP levels and temperature at D0 $($ score $=0.068 \times \mathrm{D} 0 \quad \mathrm{PCT}+0.005 \times \mathrm{D} 0 \mathrm{CRP}+0.7 \times \mathrm{Tem}-$ perature D0). The AUC for this composite score was 0.90, the best cut-off for the composite score was 28, resulting in a sensitivity/specificity of $80 \% / 97 \%$. Similarly to D0 values, although AUCs for $\triangle \mathrm{CRP}$ and $\triangle \mathrm{PCT}$ were not statistically different $(0,83$ and 0,85$), \triangle \mathrm{PCT}$, with a $>0.49 \mathrm{ng} / \mathrm{mL}$ threshold resulted in a low sensitivity/ high specificity of $68 \% / 94 \%$ while $\triangle \mathrm{CRP}$, with a threshold $>12 \mathrm{mg} / \mathrm{L}$, resulted in high sensitivity/low specificity of $92 \% / 71 \%$ for identifying nosocomial infection.

\section{Discussion}

By studying simple and routinely used clinical and biological markers of infection in patients with confirmed nosocomial infection compared to non-infected ICU patients we determined that three parameters, temperature $>38.6^{\circ} \mathrm{C}, \mathrm{PCT}>1.86 \mathrm{ng} / \mathrm{mL}$, and CRP $>88 \mathrm{mg} / \mathrm{L}$, could perform well in discriminating infected from non-infected patients (AUCs of 0.88, 0.84, and 0.88 respectively). The complementary sensitivity/specificity profiles of each marker (76\%/94\% for fever, $68 \% /$ $91 \%$ for PCT, and $92 \% / 70 \%$ for CRP) allowed the construction of a composite score $($ score $=0.068 \times \mathrm{D} 0 \mathrm{PCT}+$ $0.005 \times \mathrm{D} 0 \mathrm{CRP}+0.7 \times$ temperature) more discriminating and highly specific than each single component (AUC of 0.90 and sensitivity of $97 \%$ ).

Given the absence of any gold standard of infection we used the same methodology as Povoa et al. [7] and distinguished between patients with a confirmed diagnosis of noscomial infection, with all the limitations inherent to diagnosis of infection in the ICU, and patients discharged from the ICU without being treated by antimicrobials and therefore very unlikely to be infected.

Although one of the most frequently measured parameters in the ICU setting and non invasive, body temperature remains a poor indicator of infection [9]. Temperature can be influenced by a number of noninfectious factors, such as non-infectious causes of fever and antipyretic therapy [10]. Nevertheless, in the present study, temperature appeared to perform reasonably well for identifying nosocomial infection, with an AUC of 0.88 . The best temperature cut-off value was $38.6^{\circ} \mathrm{C}$, resulting in a sensitivity-specificity of $76 \% / 94 \%$.

Our data support the view of some authors that leucocyte count has little value in discriminating patients with nosocomial infection [7]. In our study, AUC of WBC was 0.62 , indicating that $\mathrm{WBC}$ was close to the line of non discrimination.

PCT is secreted as part of the systemic inflammatory response to infection and serum values are greatly based on the type and severity of infection. Interpretation of the literature is further complicated by frequent discrepancies or variations in the choice of the cut-off value of PCT, etiologies of infection, severity of infection, and study populations [11,12]. Serum values of PCT vary greatly based on the type and severity of infection. The highest PCT concentrations have been reported in patients with septic shock, and patients with severe sepsis had significantly higher PCT levels than patients with sepsis or SIRS [13].

Table 4 Diagnosis accuracy of serum PCT, CRP, WBC, body temperature, $\triangle C R P$ and $\triangle P C T$ for diagnosis of ICU-acquired infection

\begin{tabular}{|c|c|c|c|c|c|c|}
\hline & AUC & Cut-off level & Sensitivity (\%) & Specificity (\%) & PPV & NPV \\
\hline PCT DO & 0.84 & $1.86 \mathrm{ng} / \mathrm{mL}$ & 68 & 91 & 68 & 91 \\
\hline CRP DO & 0.88 & $88 \mathrm{mg} / \mathrm{L}$ & 92 & 70 & 47 & 97 \\
\hline WBC D0 & 0.62 & $12120 / \mathrm{mm}^{3}$ & 64 & 68 & 36 & 87 \\
\hline Temperature D0 & 0.88 & $38.6^{\circ} \mathrm{C}$ & 76 & 94 & 79 & 94 \\
\hline Composite score D0 & 0.90 & 28 & 80 & 97 & 87 & 94 \\
\hline$\overline{\triangle P C T}$ & 0.83 & $0.49 \mathrm{ng} / \mathrm{mL}$ & 68 & 94 & 77 & 91 \\
\hline$\overline{\Delta C R P}$ & 0.85 & $12 \mathrm{mg} / \mathrm{L}$ & 92 & 71 & 48 & 97 \\
\hline
\end{tabular}

Data are presented as \% unless otherwise stated. AUC: area under the receiver-operating-characteristic curve; NPV: negative predictive value; PPV: positive predictive value. 

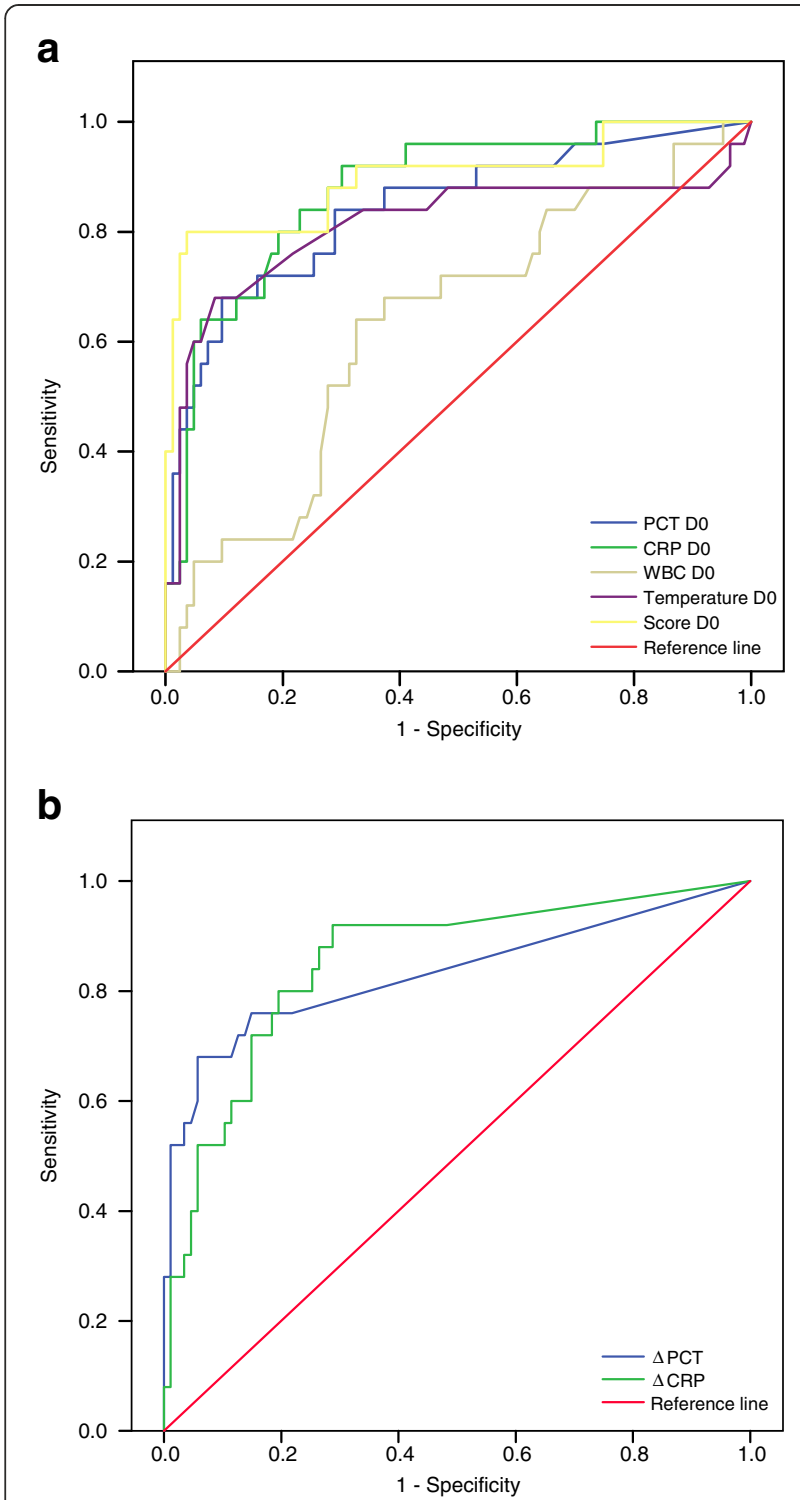

Figure 2 Receiver operating characteristic (ROC) curves comparing markers' ability to detect ICU-acquired infections, a) ROC curves comparing PCT, CRP, WBC, temperature, and composite score, b) ROC curves comparing $\triangle \mathrm{PCT}$ and $\triangle \mathrm{CRP}$ for detection of ICU-acquired infections.

In the present study, we used an ultrasensitive assay for PCT, capable of measuring low levels to identify even "subclinical" inflammatory states before the development of clinically evident sepsis. The best cut-off value of PCT for identifying ICU-acquired infection was $1.86 \mathrm{ng} / \mathrm{mL}$, with high specificity (91\%) but low sensitivity (68\%).

Few studies have analysed the behaviour of PCT in nosocomial ICU-acquired infection. In cardiac surgery patients, PCT measurement was found a reliable marker for diagnosis of infection: with a cut-off of $1 \mathrm{ng} / \mathrm{mL}$ allowing a sensitivity of $85 \%$ and a specificity of $95 \%$ [14]. In another study, PCT was useful in the diagnosis of VAP with a cuff-off value of $3.9 \mathrm{ng} / \mathrm{mL}$ allowing a specificity of $100 \%$ at the cost of a sensitivity of $41 \%$ [15].

In a recent study assessing PCT monitoring in the early diagnosis of nosocomial infection, $\mathrm{PCT}$ at D0 was the best predictor of proven infection. A cut-off value of $0.44 \mathrm{ng} / \mathrm{mL}$ provided sensitivity and specificity of $65.2 \%$ and $83 \%$, respectively for discriminating patients with proven nosocomial infection from clinically suspected but non-proven nosocomial infection [16].

Several reports suggested that PCT should replace CRP as a marker of infection in the ICU setting $[17,18]$. In certain situations, especially to differentiate bacteremic from non-bacteremic infections, PCT was reported to be superior to CRP [19]. A cut-off value of $0.4 \mathrm{ng} / \mathrm{mL}$ was associated with a negative predictive value of $98 \%$. However, well-designed studies have shown that PCT is neither a better nor an earlier diagnostic marker of infection than CRP [20-22].

In a previous meta-analysis performed by Tang et al., PCT could not reliably differentiate sepsis from other non-infectious causes of systemic inflammatory response syndrome in critically ill adult patients [23]. On the other hand, in another review, PCT concentration was found to be better than CRP for diagnosis of bacterial infection [12]. However, this review included studies across a wide range of age group, clinical setting and spectrum diseases: $46 \%$ were paediatric patients and $57 \%$ did not have SIRS. Additionally, in some clinical situations of infectious origin commonly found in ICU, PCT can be normal or even undetectable early course of infections [24], localised infections [25], or subacute endocarditis [19,26,27].

CRP is an acute-phase protein, member of the pentraxin family of proteins, whose hepatic synthesis is triggered by cytokine release due to any cause of inflammation, infectious or not. In the present study, CRP D0 had the highest AUC (0.88) and a cut-off of $88 \mathrm{mg} / \mathrm{L}$ had a sensitivity of $92 \%$ and a specificity of $70 \%$ to identify patients with ICU-acquired infection. Povoa et al. studied the role of CRP to detect infections in critically ill patients [28]. In that study, the combination of CRP $>87 \mathrm{mg} / \mathrm{L}$ and body temperature $>38.2^{\circ} \mathrm{C}$ was associated with infection diagnosis with a specificity of $100 \%$. A study using the methodology we based our study upon, found that daily CRP monitoring could be used as a marker of infection prediction [7]. Patients presenting maximum daily CRP variation $>4.1 \mathrm{mg} / \mathrm{dL}$ and a CRP level $>87 \mathrm{mg} / \mathrm{L}$ had an $88 \%$ risk of infection.

As all preceding studies we have confirmed that no single parameter or biomarker can reliably assist the clinician in diagnosing infection in the ICU. This is most probably due to: the lack of any possible gold standard for the diagnosis of infection and the extreme heterogeneity of infection in the ICU as to causal pathogen, 
underlying diseases, host-response, therapy, evolution and outcome. Facing these problems, our subsequent combination of diagnostic makers appears a useful approach to improve the accuracy in diagnosing nosocomial infection in ICU patients. Our results showed that combining PCT, CRP and temperature D0 was discriminant (highest AUC $=0.90$ ) and highly specific (specificity of $97 \%$ ). We found in our study a complementarity of CRP and PCT, with low specificity/high sensitivity for PCT and high sensitivity/low specificity for CRP. Such a combined clinical and multibiomarker approach for prediction has been proposed in another highly heterogenous complex disease in the ICU: adult respiratory distress syndrome (ARDS). Ware et al., studying the prediction of mortality in the ARDS cohort from the NHLBI studies, found that a combination of biomarkers and clinical predictors was superior to clinical predictors or biomarkers alone [29].

Some limitations of the present investigation should be noted. Our findings are based on a single centre study, one should be cautious in or extrapolating these data. Our findings cannot be generalised to specific diseases (pancreatitis, burns) or settings (cardiovascular surgical patients, neonatal/paediatric patients). Due to our study design, our findings might be only applicable to patients with late-onset nosocomial infection. Likewise, our focus on late-onset nosocomial infection led to a small number (17\%) of documented infections which could also be a limitation.

It must also be acknowledged that CRP at D0 had a negative predictive value higher than our composite score $(97 \%$ vs. $94 \%)$, showing that low CRP, under the threshold of $88 \mathrm{mg} / \mathrm{L}$ could assist clinicians in eliminating the diagnosis of nosocomial infection. However, the composite score had by far the highest positive predictive value ( $87 \%$ vs. $47 \%$ ), suggesting that it could best be used in encouraging clinicians to initiate antimicrobial therapy when faced with a suspected diagnosis of nosocomial infection and a CRP over $88 \mathrm{mg} / \mathrm{L}$.

\section{Conclusion}

The sequential measurements of serum PCT and CRP might be reliable and complementary biomarkers in early identification of ICU-acquired nosocomial infection. Combining CRP and PCT levels with temperature is an original approach which may increase diagnostic specificity. More prospective and large-scale studies are required to define the best approach.

\footnotetext{
Abbreviations

ICU: Intensive Care Unit; SIRS: Systemic inflammatory response syndrome; PCT: Procalcitonin; CRP: C-reactive protein; WBC: White blood cell count (WBC); VAP: Ventilator-associated pneumonia; SOFA: Sequential Organ Failure Assessment score.
}

\section{Competing interests}

The authors declare that they have no competing interests.

\section{Authors' contributions}

$\mathrm{RL}$ collected and analyzed the data, developed the study design and was the principal writer of the manuscript. SC collected and analyzed the data. KE was involved in the drafting of the manuscript, the discussion and the results. DM was involved in the construction of the protocol. FF critically reviewed the manuscript and was involved because of his expertise in the field. All authors read and approved the final version of the manuscript.

\section{Author details}

'Service de Réanimation Polyvalente, Centre Hospitalier Universitaire de Lille, 59000 Lille, France. ${ }^{2}$ Service de Réanimation Chirurgicale, Centre Hospitalier Universitaire de Lille, 59000 Lille, France. ${ }^{3}$ Service de Médecine Nucléaire, Centre Hospitalier Universitaire de Lille, 59000 Lille, France. ${ }^{4}$ Service de Réanimation Polyvalente, Hôpital Roger Salengro - Centre Hospitalier Universitaire de Lille, Rue Emile Laine, 59037 Lille, Cedex France.

Received: 13 March 2012 Accepted: 4 March 2013

Published: 2 April 2013

\section{References}

1. Kumar A, Zarychanski R, Light B, Parrillo J, Maki D, Simon D, Laporta D, Lapinsky S, Ellis P, Mirzanejad Y, Martinka G, Keenan S, Wood G, Arabi Y, Feinstein D, Kumar A, Dodek P, Kravetsky L, Doucette S, Cooperative Antimicrobial Therapy of Septic Shock CATSS Database Research Group: Early combination antibiotic therapy yields improved survival compared with monotherapy in septic shock: a propensity-matched analysis. Crit Care Med 2010, 38:1773-1785.

2. Calandra T, Cohen J, International Sepsis Forum Definition of Infection in the ICU Consensus Conference: The international sepsis forum consensus conference on definitions of infection in the intensive care unit. Crit Care Med 2005, 33:1538-1548.

3. Luna CM, Vujacich P, Niederman MS, Vay C, Gherardi C, Matera J, Jolly EC: Impact of BAL data on the therapy and outcome of ventilator-associated pneumonia. Chest 1997, 111:676-685.

4. American Thoracic Society: Guidelines for the management of adults with hospital-acquired, ventilator-associated, and healthcare-associated pneumonia. Am J Respir Crit Care Med 2005, 171:388-416.

5. Martin MA, Pfaller MA, Wenzel RP: Coagulase-negative staphylococcal bacteremia. Mortality and hospital stay. Ann Intern Med 1989, 110:9-16.

6. Garner JS, Jarvis WR, Emori TG, Horan TC, Hughes JM: CDC definitions for nosocomial infections, 1988. Am J Infect Control 1988, 16:128-140.

7. Povoa P, Coelho L, Almeida E, Fernandes A, Mealha R, Moreira P, Sabino H: Early identification of intensive care unit-acquired infections with daily monitoring of C-reactive protein: a prospective observational study. Crit Care 2006, 10:R63.

8. Cohen J, Guyatt G, Bernard GR, Calandra T, Cook D, Elbourne D, Marshall J, Nunn A, Opal S, UK Medical Research Council International Working Party: New strategies for clinical trials in patients with sepsis and septic shock. Crit Care Med 2001, 29:880-886.

9. Circiumaru B, Baldock $G$, Cohen J: A prospective study of fever in the intensive care unit. Intensive Care Med 1999, 25:668-673.

10. Marik PE: Fever in the ICU. Chest 2000, 117:855-869.

11. Assicot M, Gendrel D, Carsin H, Raymond J, Guilbaud J, Bohuon C: High serum procalcitonin concentrations in patients with sepsis and infection. Lancet 1993, 341:515-518.

12. Simon L, Gauvin F, Amre DK, Saint-Louis P, Lacroix J: Serum procalcitonin and C-reactive protein levels as markers of bacterial infection: a systematic review and meta-analysis. Clin Infect Dis 2004, 39:206-217.

13. Brunkhorst FM, Wegscheider K, Forycki ZF, Brunkhorst R: Procalcitonin for early diagnosis and differentiation of SIRS, sepsis, severe sepsis, and septic shock. Intensive Care Med 2000, 26:S148-S152.

14. Aouifi A, Piriou V, Bastien O, Blanc P, Bouvier H, Evans R, Célard M, Vandenesch F, Rousson R, Lehot JJ: Usefulness of procalcitonin for diagnosis of infection in cardiac surgical patients. Crit Care Med 2000, 28:3171-3176.

15. Duflo F, Debon R, Monneret G, Bienvenu J, Chassard D, Allaouchiche B: Alveolar and serum procalcitonin: diagnostic and prognostic value in ventilator-associated pneumonia. Anesthesiology 2002, 96:74-79.

16. Charles PE, Kus E, Aho S, Prin S, Doise JM, Olsson NO, Blettery B, Quenot JP: Serum procalcitonin for the early recognition of nosocomial infection in the critically ill patients: a preliminary report. BMC Infect Dis 2009, 9:49. 
17. Luzzani A, Polati E, Dorizzi R, Rungatscher A, Pavan R, Merlini A: Comparison of procalcitonin and C-reactive protein as markers of sepsis. Crit Care Med 2003, 31:1737-1741

18. Oberhoffer M, Karzai W, Meier-Hellmann A, Bögel D, Fassbinder J, Reinhart K: Sensitivity and specificity of various markers of inflammation for the prediction of tumor necrosis factor-alpha and interleukin- 6 in patients with sepsis. Crit Care Med 1999, 27:1814-1818.

19. Chirouze C, Schuhmacher H, Rabaud C, Gil H, Khayat N, Estavoyer JM, May T, Hoen B: Low serum procalcitonin level accurately predicts the absence of bacteremia in adult patients with acute fever. Clin Infect Dis 2002, 35:156-161.

20. Ugarte H, Silva E, Mercan D, De Mendonça A, Vincent JL: Procalcitonin used as a marker of infection in the intensive care unit. Crit Care Med 1999, 27:498-504.

21. Suprin E, Camus C, Gacouin A, Le Tulzo Y, Lavoue S, Feuillu A, Thomas R: Procalcitonin: a valuable indicator of infection in a medical ICU? Intensive Care Med 2000, 26:1232-1238.

22. Hambach L, Eder M, Dammann E, Schrauder A, Sykora KW, Dieterich C, Kirschner P, Novotny J, Ganser A, Hertenstein B: Diagnostic value of procalcitonin serum levels in comparison with C-reactive protein in allogeneic stem cell transplantation. Haematologica 2002, 87:643-651.

23. Tang BM, Eslick GD, Craig JC, McLean AS: Accuracy of procalcitonin for sepsis diagnosis in critically ill patients: systematic review and metaanalysis. Lancet Infect Dis 2007, 7:210-217.

24. Christ-Crain M, Jaccard-Stolz D, Bingisser R, Gencay MM, Huber PR, Tamm M, Müller B: Effect of procalcitonin-guided treatment on antibiotic use and outcome in lower respiratory tract infections: cluster-randomised, single-blinded intervention trial. Lancet 2004, 363:600-607.

25. Söderquist B, Jones I, Fredlund H, Vikerfors T: Bacterial or crystal-associated arthritis? Discriminating ability of serum inflammatory markers. Scand J Infect Dis 1998, 30:591-596.

26. Debard AL, Vautrin C, Pariset C, Bienvenu J, Monneret G: High serum procalcitonin levels do not predict bacteremia in adult patients with acute fever. Clin Infect Dis 2003, 36:825-826.

27. Cheval C, Timsit JF, Garrouste-Orgeas M, Assicot M, De Jonghe B, Misset B, Bohuon C, Carlet J: Procalcitonin (PCT) is useful in predicting the bacterial origin of an acute circulatory failure in critically ill patients. Intensive Care Med 2000, 26:S153-S158.

28. Povoa P, Coelho L, Almeida E, Fernandes A, Mealha R, Moreira P, Sabino H: C-reactive protein as a marker of infection in critically ill patients. Clin Microbiol Infect 2005, 11:101-108.

29. Ware LB, Koyama T, Billheimer DD, Wu W, Bernard GR, Thompson BT, Brower RG, Standiford TJ, Martin TR, Matthay MA, NHLBI ARDS Clinical Trials Network: Prognostic and pathogenetic value of combining clinical and biochemical indices in patients with acute lung injury. Chest 2010 137:288-296.

doi:10.1186/1471-2334-13-159

Cite this article as: Robriquet et al:: A composite score combining procalcitonin, C-reactive protein and temperature has a high positive predictive value for the diagnosis of intensive care-acquired infections. BMC Infectious Diseases 2013 13:159.

\section{Submit your next manuscript to BioMed Central and take full advantage of:}

- Convenient online submission

- Thorough peer review

- No space constraints or color figure charges

- Immediate publication on acceptance

- Inclusion in PubMed, CAS, Scopus and Google Scholar

- Research which is freely available for redistribution

Submit your manuscript at www.biomedcentral.com/submit
C Biomed Central 